\title{
El campamento romano de la Vía Carisa en Asturia Transmontana
}

\author{
Jorge Camino Mayor, Rogelio Estrada García \\ Y YOLANDA VINIEGRA PACHECO
}

\begin{abstract}
RESUMEN ABSTRACT
Un largo cordal que desde el corazón de la cordillera Cantábrica, en el norte de la Península lbérica, llega al centro de la región asturiana conserva unos sorprendentes restos arqueológicos a

1.700 y $1.800 \mathrm{~m}$ de altura, a los que se vienen dando diversas interpretaciones poco satisfactorias. El estudio de tales yacimientos permite su identificación con un campamento romano y una vía estratégica, cuya construcción hay que atribuir a Publio

Carisio, los cuales forman parte de una gran operación militar para la conquista de la región que los romanos llamaron Asturia Transmontana. Constituye la primera evidencia arqueológica del Bellum Asturicum y el primer testimonio de la

In the heart of a Northern Spanish mountain range, a tailpiece of which reaches the centre of the region Asturias, at 1.700 and $1.800 \mathrm{~m}$ altitude are some surprising archaeological remains. For which some diverse, but not wholly satisfactory, interpretations have been made. The examination of these remains has identified a Roman summer encampment and one strategic road, each construction directed by Publio Carisio and formed a part of a grand military operation, the conquest of the region the Romans called Asturia Transmontana. The first archaeological evidence of the Bellum Asturicum and the testament to Asturias as the scenery to the first the bélico theatre.
\end{abstract} escenificación en Asturias del teatro bélico. 


\section{EL CASTICHU COMO CASTRO INDÍGENA}

El enclave fortificado de El Castichu ${ }^{1}$ de La Carisa o del Monte Curriechos es conocido desde mediado el siglo XIX, momento en el que es referenciado como un reducto de la población indígena durante la conquista romana (Tuñón y Quirós, 1858a). Justo un siglo después el lugar quedó etiquetado dentro de la tipología castreña en el primer catálogo regional de esta clase de yacimientos (González, 1966) y como tal fue analizado en los sucesivos trabajos centrados en dicha cuitura (González, 1978; Maya, 1983 y 1988). La causa de esa asimilación ha de buscarse en dos atributos comunes con los castros: por un lado, la disposición concéntrica de algunos de los fosos y terraplenes que integran sus defensas $y$, por otro, su localización en una cumbre montañosa. Es cierto que sus características peculiares, cuando no extremas, merecieron frecuentes comentarios interpretativos que realzaban su originalidad, pero solían servir también para inducir modelos teóricos acerca de los modos de vida castreños.

Sin duda, lo que más llamó la atención fue su ubicación en una desolada cumbre a $1.728 \mathrm{~m}$ de altitud e inmediata a la zona axial de la cordillera Cantábrica, donde la nieve y el hielo arraigan durante unos seis meses al año (Tuñón y Quirós, 1858). La inevitable ocupación temporal a que ese hecho daba lugar, bajo el sesgo de la mentalidad de aquella época, fue explicada dentro de los acontecimientos de las Guerras Cántabras (Ibidem), creencia que fue modernamente arrinconada para hacer valer una utilidad estacional especializada en actividades ganaderas de época prerromana (Maya, 1983), sin descartar la importancia estratégica que pudo tener en tiempos romanos su proximidad a una importante ruta de paso a través de la Cordillera (Ibidem, 1988). La excepcional captura de un manantial dentro del recinto por unas líneas de defensa externas (González, 1966) tenía pleno sentido para garantizar la permanencia estival (Maya, 1983).

Tampoco pasó desapercibida la configuración de las defensas con fosos dobles, al menos en el caso de las externas (González, 1966 y 1978 ), sin que ello originase mayor quebranto con los sistemas fortificativos castreños.

\footnotetext{
Por el momento no hemos encontrado confirmación a la denominación El Castichu como suele ser conocido el yacimiento. El topónimo Curriechos, que es como se conoce el lugar entre los vecinos y del que se hizo eco Tuñón y Quirós, deriva de corros, diversos tipos de construcciones ganaderas de planta circular. Al no haber constancia de las mismas en esa parte de la sierra, es posible que se le diese ese nombre por la forma curva de las defensas concéntricas.
} 


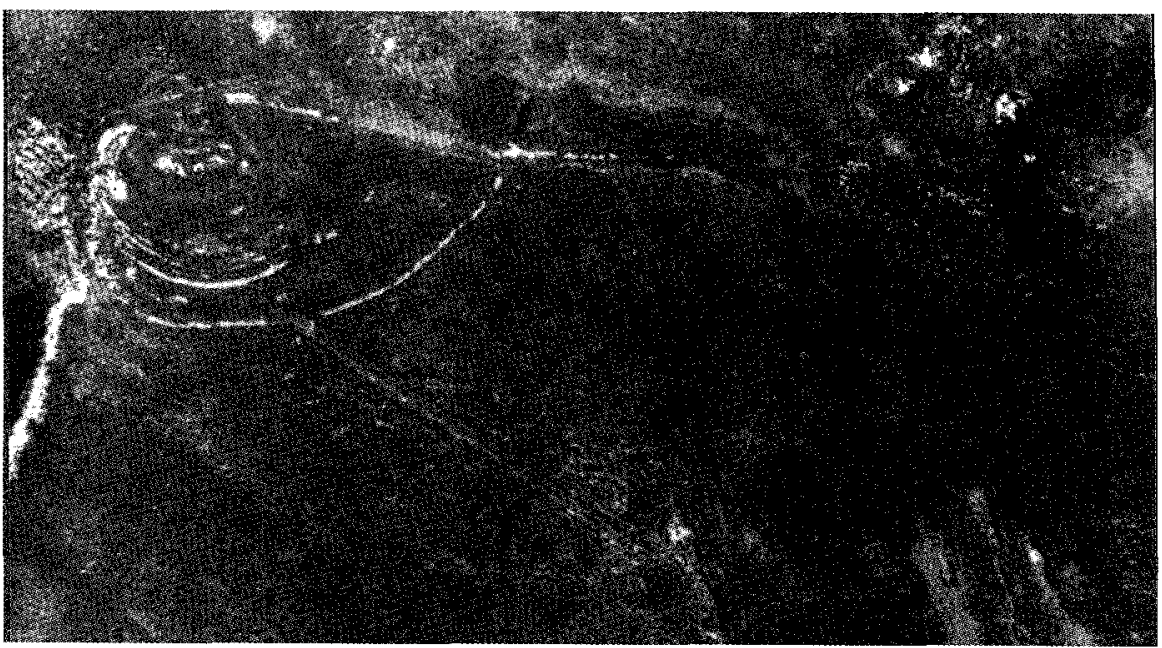

Foto 1. Ampliación del fotograma realizado en un vuelo del año 1970, con buena definición de las estructuras defensivas.

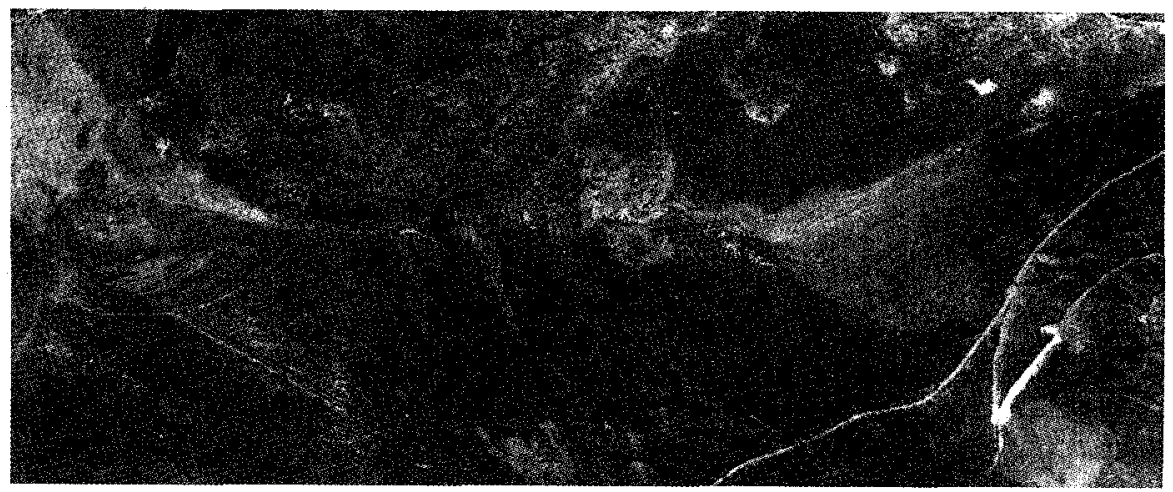

Foto 2. Fotograma del vuelo de 1994, también aumentado. Debido al recubrimiento vegetal ya no es tan apreciable el vallum más meridional, en cambio si lo son las estructuras de más al sur (derecha).

\section{EL CAMPAMENTO ROMANO}

Es, precisamente, la morfología de las obras defensivas la que facilita la base empírica que permite reinterpretar los restos del Monte Curriechos como pertenecientes a instalaciones campamentales del ejército romano. Hasta ahora la única descripción realizada consistía en un somero croquis que, por eso mismo, reflejaba una realidad parcial a una escala desi- 


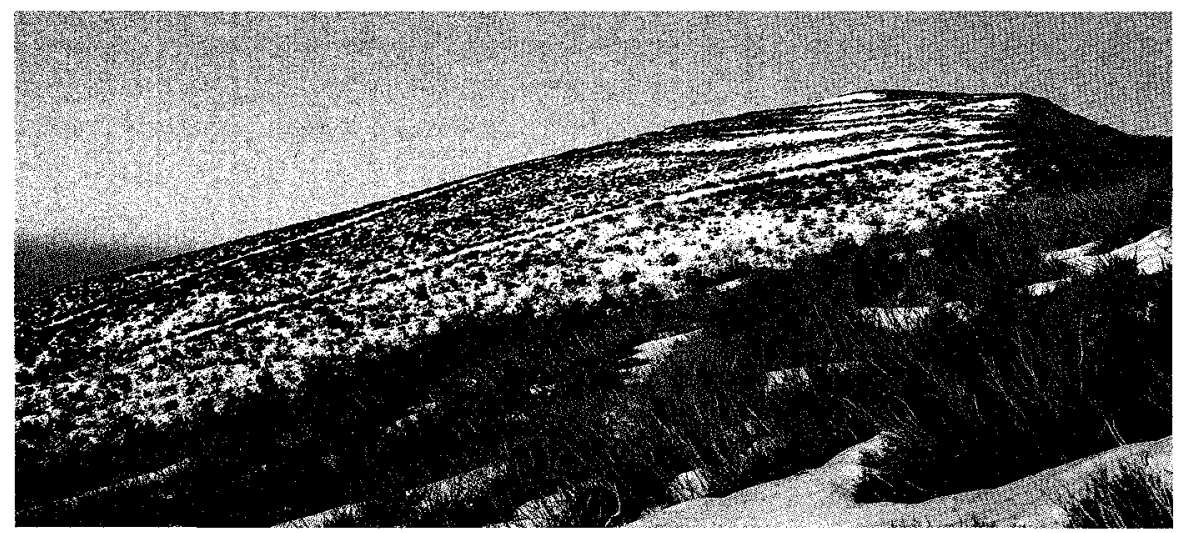

Foto 3. Vista general del campamento desde el S.

gual (González, 1978). Para comprender las peculiaridades reflejadas por la planta del dispositivo defensivo dentro de los hábitos castramentales es preciso reparar en las condiciones del soporte topográfico. El emplazamiento comprende una amplia loma en la dorsal de un estrecho y largo cordal que desde el eje de la Cordillera se alinea hacia el NNO. El cerro, de suaves formas redondeadas presenta, sin embargo, un escarpe agudo en su lado oriental que desemboca en una plataforma de deslizamiento. El emplazamiento de campamentos en relieves dominantes, no tan escabrosos que dificultaran las instalaciones, era costumbre inveterada entre los romanos, especialmente en circunstancias de campaña para favorecer el dominio estratégico (César, B.G., II, 8, 18, III, 19; Tácito, H., IV, 23)

Las fortificaciones se han venido dividiendo en dos grupos. De una parte, un sistema de tres barreras concéntricas, dos interiores seguidas y una exterior más separada que, conformes a las curvas de nivel, rodean el cerro hasta el acantilado oriental. De otra, dos líneas adelantadas de fosos dobles que confluyen en ángulo oblicuo en la ladera SO, encontrándose en su vértice la fuente. Justamente esa propiedad de fosos dobles es la que reporta una primera caracterización arqueológica del yacimiento, pues responden por tamaño y fisonomía a los patrones de las fossae duplex habituales en los campamentos romanos. En ambos casos se trata de dos fosos cóncavos de poco más de cinco metros de anchura superior y de un metro de profundidad separados por un estrecho caballete. No es plausible que la profundidad de los fosos haya sido originalmente mucho mayor, pues al actuar como cauces de la escorrentía apenas han permitido la deposición de sedimentos, aunque sí es previsible que respondan a los per- 
files en $\mathrm{V}$ propios del tipo fastigata. En ambas líneas la fossa interna remata en un agger de apenas un par de metros de altura y algo alzado sobre el recinto.

El esquema de los fosos dobles no se reduce a las defensas exteriores, sino que también concierne a las interiores, reconocibles aún a pesar de su distorsionado estado actual por la colmatación que su trazado horizontal facilitó en mayor grado que los anteriores. En efecto, en cada una de ellas se aprecia un foso externo al que sigue un escalón amesetado, de anchura similar a aquél, y previo al agger culminante. Como la posición de esos replanos a medio talud es anómala para corresponder a bermas, lo más probable es que respondan a fossae cegadas tal como se presentan en otros lugares, con lo que es dado suponer que las tres defensas concéntricas consten de fossa duplex. Todavía es posible añadir que tras algunas de las líneas defensivas se definen pequeños pasillos que han de equivaler a los respectivos intervalla ${ }^{2}$.

Junto a estos componentes que ya eran parcialmente conocidos, la realidad arqueológica observable es, con todo, más numerosa. En primer lugar cabe aludir a la explanada de la cumbre del monte que da la impresión de haber servido de recinto singularizado a juzgar por su diseño topográfico y la aparición de piedras en su derredor. Más interesante es la plataforma situada en la zona S. de la loma, pero ya con caída al lado oriental y bordeando el plano de deslizamiento, que está recortada al $\mathrm{N}$. y E. por un vallum de foso y terraplén, en un tramo con bastantes metros de altura, que en unión a la espina del cordal acaba cerrando una superficie subrectangular.

Otro objeto de atención, por su manifiesta individualización en esta clase de instalaciones, fue la búsqueda de la entrada que, aunque discreta, puede ser en gran medida distinguida. Esta se realiza desde el $\mathrm{S}$ a lo largo de la tendida arista del cordal. Allí los sucesivos valla se interrumpen o arquean ligeramente para dejar un paso de algo más de un par de metros flanqueado al $\mathrm{E}$ por el recinto de la plataforma acabada de referir. Incluso ante el vallum externo de la serie concéntrica se aprecia un tramo de fossa que debe señalar la comparecencia de un titulum.

Finalmente, a pesar de su incierta naturaleza, es preciso aludir a una especie de doble surco que recorre un largo tramo de la ladera occidental de una loma emplazada al $\mathrm{S}$ del campamento, detectado gracias a las fo-

\footnotetext{
2 Tras el desbroce íntegro de las defensas y posterior excavación hay que matizar que las tres líneas concéntricas consisten en realidad en un vallum externo de fossa duplex y en otra de fossa cuadruplex, ambas dotadas de camino de ronda.
} 
tografías aéreas. Por desgracia, la espesura y el manto nival impidieron la efectividad de la exploración que tan sólo reveló un segmento de dos escalones paralelos que se interrumpen bruscamente en la pendiente y están muy afectados por al erosión. A pesar de la incertidumbre, la sospecha de su relación con otro recinto campamental es inevitable y habrá de ser resuelta en el futuro.

El trazado de las fortificaciones origina una articulación compleja de varios recintos que pueden ser comprendidos en tres principales: el central que incluye la cumbre, su prolongación hasta el vallum duplex y la franja hasta el vallum externo de los concéntricos-, el amplio espacio comprendido entre los valla de la ladera SO y, por último, la plataforma del costado oriental. Obviamente, resta por determinar el carácter de los indicios del monte meridional. Sin contar este último, la superficie construida se acerca a cinco hectáreas y, aunque una cuantía nada desdeñable es ocupada por las propias defensas, el espacio habitable debe aproximarse a 3 ha.

Un detalle que es oportuno consignar reside en que la unión del gran recinto meridional con el nuclear ocasionó alguna disconformidad en la articulación de las defensas. En efecto, el vallum occidental del espacio exterior se inicia cortando transversalmente doble fosa concéntrica más externa en vez de adosarse sin más, aunque ello no implique su anulación funcional. Sin que sea posible aún establecer las consecuencias reales de ese hecho, es evidente que entre la construcción de ambos recintos medió un lapso temporal que quizás explique también sus diferencias morfológicas.

Como se dijo, la tipología de construcciones defensivas se encuadra sin reserva en el canon castramental que el ejército romano plasmó en numerosos ejemplos de Britania, el Rin (Webster, 1988) y la Galia (Reddé, 1999). Más determinante resulta su coincidencia con las fortificaciones que en la última década se vienen conociendo en las instalaciones relacionadas con la conquista y dominio del norte hispánico, particularmente en Asturica Augusta (González, 1999), Petavonium (Carretero y Romero Carnicero, 1996) o los campamentos operativos como el de Valdemeda en el occidente leonés (Sánchez-Palencia, 1986) y los de ofensiva recientemente localizados en Cantabria (Peralta, 1999). Por contra, salta a la vista su diferencia con las fortificaciones castreñas regionales, aunque en Chao Samartín parece producirse a mitad del siglo । d.C. una reexcavación parcial del gran foso externo para formar con otro también pequeño un dispositivo de fossa duplex, evento que está siendo objeto de estudio y que pudiera relacionarse con la aparición de numerario de origen militar (Villa, 2000 e información personal de futura publicación). Igualmente, por más que se hayan buscado similitudes, es perceptible tanto la extraordinaria altura del emplazamiento del cam- 
pamento sobre los castros conocidos, incluso los más elevados que raramente superar los $1.000 \mathrm{~m}$ de altitud, como la diferencia de escala con ellos, a los que como poco triplica en tamaño.

\section{LA CARISA Y LOS HALLAZGOS ARQUEOLÓGICOS}

Si de los restos analizados se desprende el carácter campamental de los recintos fortificados del Monte Curriechos, otros testimonios arqueológicos contribuyen a reforzar el planteamiento propuesto. Entre ellos hay que referirse al casco de bronce con relieves que fue encontrado en 1849 por un vaquero en las inmediaciones de Curriellos (Tuñón y Quirós, 1858), y un objeto que fue descrito como la cimera de otro en el vecino paraje de Fuentes (Ibidem, 1860), además de una punta de lanza, también de bronce y con perforación para el mango, descubierta en la zona del puerto (Cabal, 1953). De Murias, aldea situada en el valle del río Negro (Tuñón y Quirós, 1865), o de la misma falda de la montaña de Curriechos, se hace proceder un lote de más de un centenar de denarios de Augusto y Tiberio que estaban esparcidos por el terreno (Ibidem, 1860); e igualmente de Murias en ocasión posterior otro de 180 grandes bronces de época más moderna (Ibidem). Resulta difícil valorar la relación de estos hallazgos con el campamento, aunque los objetos de bronce aparecidos en la sierra, en especial los cascos, se avengan bien con el equipamiento militar propio de esa clase de instalaciones. En cuanto al numerario, tanto su cronología imperial como su aparición más alejada entrañan reparos de superior entidad, y de hecho, el que al otro lado del valle, sobre el propio Murias, un monte sea conocido con el mismo nombre de Curriechos, puede conducir a equívocos acerca del lugar en que se efectuó el hallazgo.

Un hecho de gran trascendencia fue la identificación realizada hace unas décadas por J.M. González de un camino que atraviesa la Cordillera y desciende por el valle leonés de Camplongo en dirección al Bernesga (Diego Santos, 1978; Fernández Ochoa, 1982), contando con algunos tramos empedrados (Concepción, 1995), y que recibe la nominación de Carisa. En la zona de la divisoria el camino denominado viejo faldea la montaña a $1.750 \mathrm{~m}$ de altura y unos $150 \mathrm{~m}$ por encima del puerto de la Cochá Propinde, por donde pasa el que dicen nuevo, para discurrir al pie del campamento y seguir la cuerda montañosa hasta descender por Ujo hacia el centro de la región. La vía es el antecedente de la reflejada por el Ravennate entre Asturica Augusta y Lucus Augusti, por Asturias, reduciéndose una de las mansio, Memoriana, a la actual Mamorana, lugar del valle de Pajares bajo la sierra, y junto al cual se conocen notables construccio- 


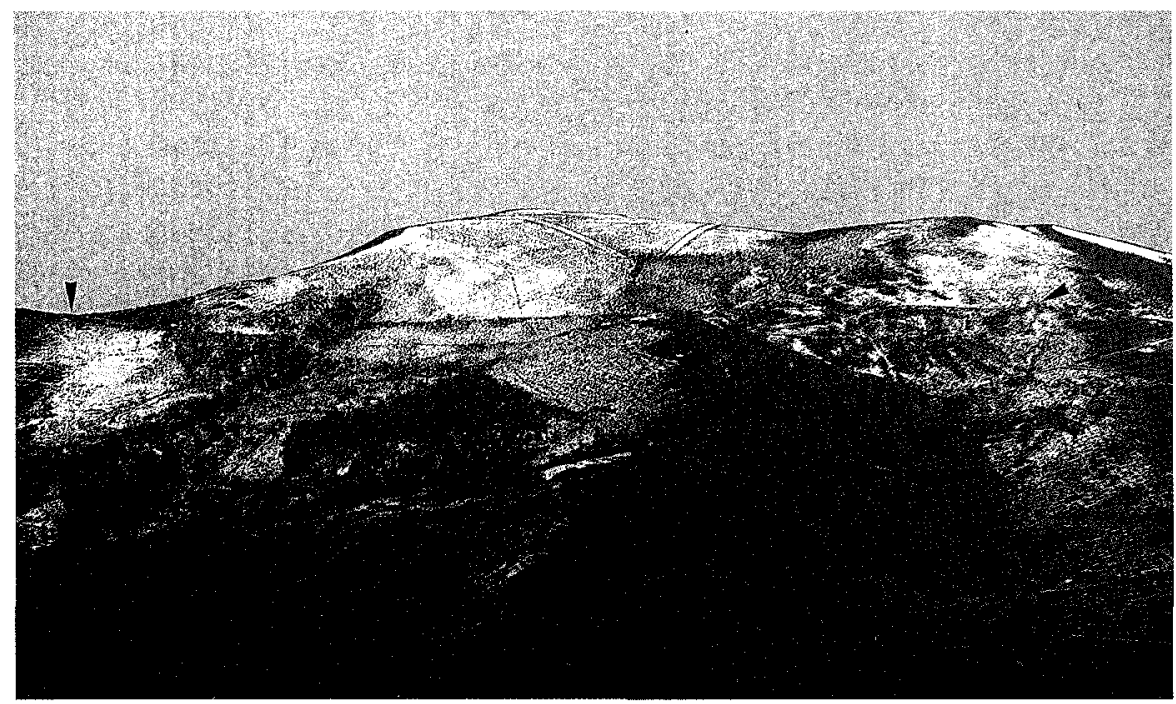

Foto 4. En esta imagen tomada desde el oeste se observan las instalaciones campamentales en lo alto del cordal. Por debajo, entre las flechas, discurre la Vía Carisa.

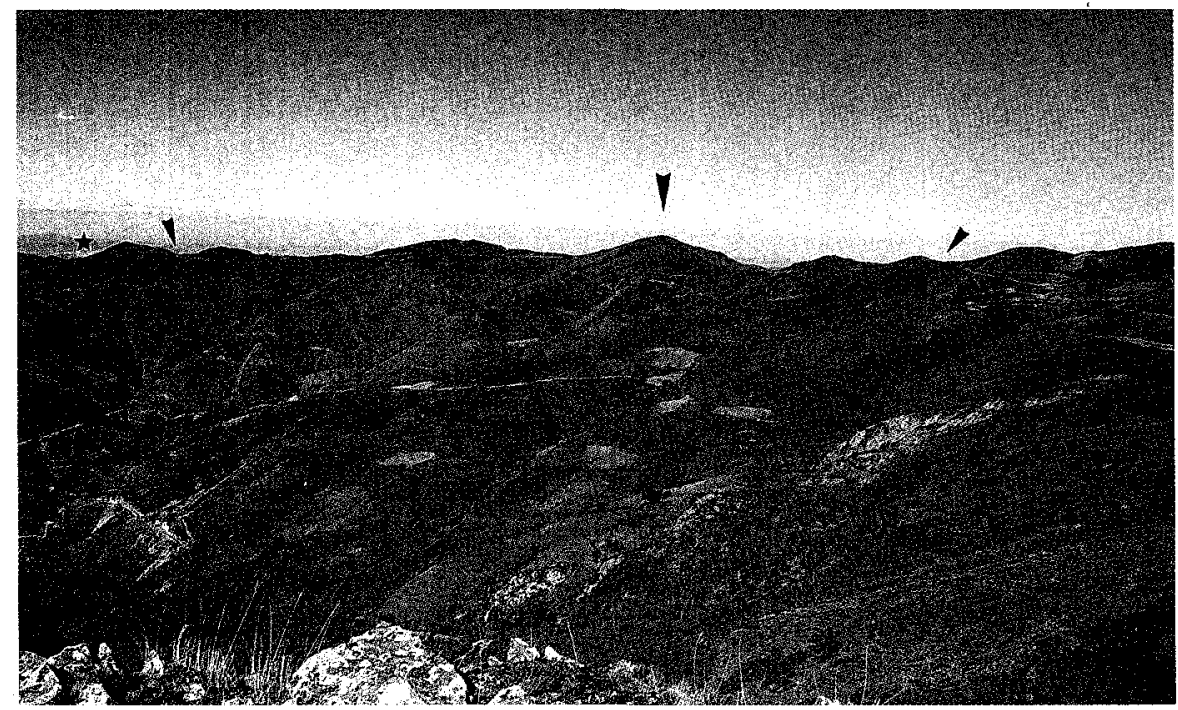

Foto 5. Panorámica desde los Pasos de Arbás, en la divisoria, del emplazamiento del campamento por encima del valle de Parana (Lena). Las flechas menores indican el curso de la vía a lo largo del cordal de Carraceo. El asterisco del fondo indica la situación de la capital regional, Oviedo. 
nes romanas. Ahora, parece acreditarse que esta histórica vía tuvo un origen genuinamente militar revelado por su servicio al campamento y su trazado a refugio por la cumbre de la sierra. Durante la guerra el tránsito de las rutas naturales a través de las montañas para llegar a la costa se ha invocado como una constante calculadamente estudiada (Forni, 1970).

Si se recuerda ahora la relación de solapamiento del vallum exterior con las defensas concéntricas y la cronología relativa que con ello se abre entre la construcción de los recintos, ¿sería dado pensar que el recinto nuclear en la colina fue el asentamiento logístico ligado a la construcción de la vía? Esta posibilidad permitiría comprender que las ampliaciones posteriores, ligadas quizá al estacionamiento de paso de las tropas no pretendiesen una ortodoxa planificación.

\section{GEOESTRATEGIA DEL CAMPAMENTO}

Si bien es cierto que la falta aún de hitos cronológicos del campamento obstruye su encuadre en un contexto histórico seguro, su mera constatación genera tantas expectativas que difícilmente se pueden eludir varias consideraciones por más que hayan de acogerse al terreno de las hipótesis.

La característica más destacada del campamento es su posición extrema, a más de $1.700 \mathrm{~m}$ de altitud y en pleno núcleo de la cordillera Cantábrica, lo que provoca una coincidencia general en aceptar una obligada ocupación temporal. Bajo este punto de vista las instalaciones se inscriben en la categoría de castra aestiva o de campaña estival. Si esto es así, parece inevitable ponerlo en relación con las acciones bélicas de conquista del territorio ástur transmontano. Ese ambiente de compromiso puede explicar la irregularidad del campamento y su ajustada adaptación al medio topográfico en una clara plasmación de castra necessaria. Con un horizonte de contienda encaja, en definitiva, no sólo la naturaleza del emplazamiento y las incomodidades inherentes, sino también su copioso aparato defensivo y la preocupación por incorporar dentro de él una surgencia de agua, algo que tiene todo su sentido ante un eventual asedio. Es indudable que a este enfoque genérico contribuyen inestimablemente los descubrimientos efectuados en regiones vecinas como el campamento de Valdemeda en el NO de la Meseta y a las puertas de Galicia (Sánchez-Palencia, 1986), y sobre todo varios de Cantabria que ilustran sobre muchos rasgos arqueológicos y de estrategia de la guerra (Peralta, 1999 y 2001).

De la situación del campamento es obligado decir algo más que abunda en la meticulosidad con que fue elegido el emplazamiento. Así y en re- 


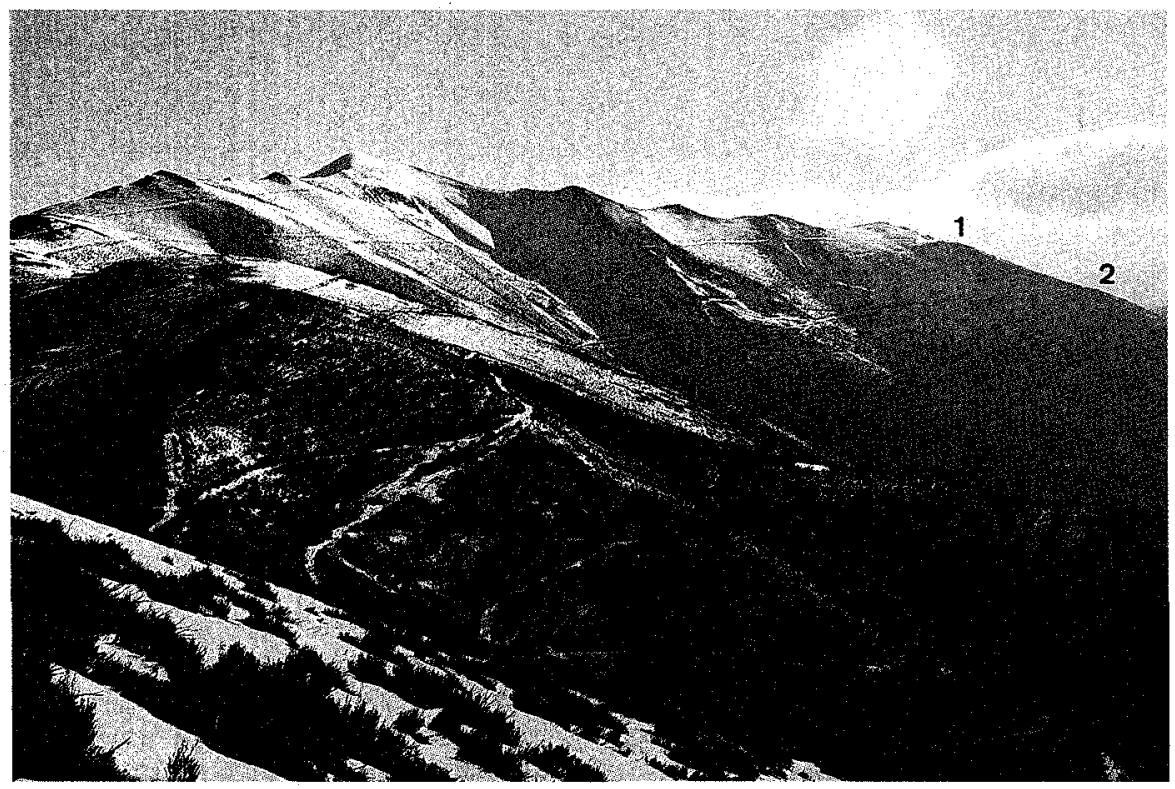

Foto 6. El eje de la Cordillera visto desde las proximidades del campamento. En 1 se ve el itinerario en altura de la vía, mientras en 2 un trazado posterior busca la collada Propinde para bajar a la Meseta.

lación con lo que viene argumentándose, es notorio que ninguna cumbre próxima ejerza un dominio altitudinal sobre la que se asienta. Además, su control territorial es impresionante y se impone a la complejidad orográfica de la mitad oriental de la región que, dicho sea de paso, en los días despejados aparece empequeñecida. De este modo, con independencia de la lógica ascendencia sobre los valles de Pajares y Negro que lo contornean más de $1.000 \mathrm{~m}$ por debajo, y si bien la visión del occidente asturiano es obstaculizada con la enfilada montañosa de las Ubiñas y el Aramo, en cambio se abarca toda la cubeta central de la región hasta el Cantábrico y, por el oriente, la totalidad de las cadenas montañosas con los Picos de Europa como telón de fondo.

Con la vía como apoyo, el castra debe obedecer, por ello, a una base de operaciones de avance, pero supone asimismo un apoyo de retaguardia, asegurando la posición y la cobertura en caso de un repliegue entre las montañas. Más allá de este planteamiento territorial no es posible precisar el objeto último del campamento, por más que pueda inferirse su incidencia sobre la abundante población indígena de los valles centrales de 
la región a juzgar por la cuantía de castros conocidos, y cuyo movimiento de contingentes podían ser anticipados. A este respecto no se han podido confirmar todavía los indicios de un foso que rodeaba un monte vecino y que en el siglo XIX fundamentó la opinión de que allí había tenido lugar el sitio bélico del Mons Medullius, lo que haría del campamento no el refugio de los sitiados como se creía (Tuñón y Quirós, 1858), sino el centro de asedio.

No obstante, si se pretendiera una conexión con los magros testimonios de los epitomistas de la conquista, es obligado aludir al acontecimiento de momento con una reducción geográfica más cercana, como es la toma de Lancia, oppidum situado unos $60 \mathrm{~km}$ al sur en la proyección natural de la vía. Sería lógico que la columna del ejército que allí operó en 25 a.C. y cuyos acuartelamientos invernales se asentaron al lado del Esla, donde sufrieron la acometida de las fuerzas transmontanas, fuera la responsable del campamento que nos ocupa. La llamativa coincidencia nominal, a la que los filólogos no oponen mayor objeción (García Arias, 2000; Concepción, 1995), de Carisa con Carisio pudiera estar denunciando al legado del cuerpo militar que venció a los ástures y se apoderó de Lancia, como autor de la apertura de la vía que entra en Asturia transmontana dentro de los episodios subsiguientes para la dominación de las tierras costeras, habiendo sugerido incluso algunos investigadores el paso de Pajares en el corazón de la Cordillera como vía obligada para ese cometido de resultas de los episodios de 26-25 a.C. (Schmitthenner cit. por Syme, 1970). El gobierno militar de Publio Carisio durante esta fase de la conquista justificaría que otorgara su nombre a la vía estratégica construida bajo su mandato.

Ahora bien, otra cuestión pendiente de comentario deriva de que el dominio posicional del campamento coincida con el territorio asignado al populus de los luggones, citado por C. Ptolomeo, que comprendía el centro de la región hasta el río Sella. ¿Querrá ello decir que la estrategia romana concibió una acción unitaria contra esta entidad grupal debido a su resistencia peculiar? A este respecto no puede obviarse la resolución de los luggones en su lucha contra suevos y visigodos en los siglos vi y VII, cuyo nombre aceptablemente pudiera esconderse bajo los términos corruptos de runcones/roccones de los códices Biclarense y San Isidoro (Diego Santos, 1978).

Quedan muchos interrogantes a la espera de las novedosas investigaciones de todo tipo que abre este campamento. Por el momento, la actual región asturiana, ajena hasta ahora a la escenografía bélica de la conquista, según las habituales exégesis de las fuentes históricas, y huérfana 
de otras pruebas arqueológicas, puede entrar de lleno en la geografía del Bellum Asturicum ${ }^{3}$.

\section{UN CAMPAMENTO ENTRE LA HISTORIA Y LA LEYENDA}

A lo largo de los tiempos, antiguos historiadores y eruditos han mostrado propensión a situar en los pasos centrales de la Cordillera hacia Asturias acontecimientos bélicos de la guerra de Roma contra cántabros y ástures.

Ya en 1695 el jesuita L.A. de Carvallo, en relación con los hechos que precedieron a la caída de Lancia, explica que, para contener la penetración del ejército romano acantonado en la Meseta, las tropas ástures se habían dividido en tres frentes, a uno de los cuales le habría correspondido la región de los montes Ebraseos - seguramente por Erbaseos-, según noticia que dice haber extraído del padre Custodio, que por su parte la habría tomado del antiguo libro de Lotario. El padre Carvallo lleva la localización de esos montes al occidente de Asturias, lo que guardaría conformidad con la supuesta ubicación de los montes Narbasos, en el caso de que sean los mismos, donde el Cronicón de Idacio cuenta que tuvo lugar en 419 el sitio de los suevos por los vándalos. Sin embargo, Jovellanos, y más tarde Caunedo, consideraban los montes Ervasios o Arbasios como la cordillera que separa Asturias y Lećn, lo que pudiera estar reputado por la abundancia del topónimo Arbás en las montañas comprendidas entre Leitariegos y Pajares y aún

3 Este artículo fue redactado a finales del invierno del año 2002, poco después que se hubiera dado la noticia por los mismos autores de la naturaleza de las fortificaciones en «El campamentu romanu d'El Castichu La Carisa: una avanzada militar n'Asturia Transmontana", Revista Asturies, págs. 25-29. En el verano de 2003, por mediación de la Obra Social y Cultura del Cajastur, se acometieron las primeras actuaciones arqueológicas en el yacimiento. El estudio de una zona de las defensas demostró su coincidencia canónica con los trabajos castramentales romanos, tanto por estructura y forma, como también por su complemento con elementos de madera característicos, cuyas cimentaciones fueron reconocidas - vallus, cervi, sudes-. Entre otros restos de equipamiento debe mencionarse el hallazgo de puntas y regatones de lanza, un dardo de ballista, proyectiles plomados de honda, azadas, dolabra, hacha y varias clavijas de tienda campaña. Por su especial significado hay que destacar un denario de Julio César, conmemorativo de su victoria sobre los germanos, y un bronce emitido en 30-29 a.C. que porta las efigies de Octaviano y Agripa. Todo ello confirma sobradamente no sólo la naturaleza castramental de las instalaciones, sino también su exacta vinculación con el Bellum Asturicum, dentro de la línea argumental planteada en este texto. Otras cuestiones trascendentes, entre las que no son menores la posible existencia de fortificaciones subyacentes al campamento y una notable barrera lineal, de clara fisonomía indígena, que un kilómetro más al $\mathrm{N}$. en una angostura de la sierra hace frente al campamento y la vía, deberán ser estudiadas en los próximos años. 


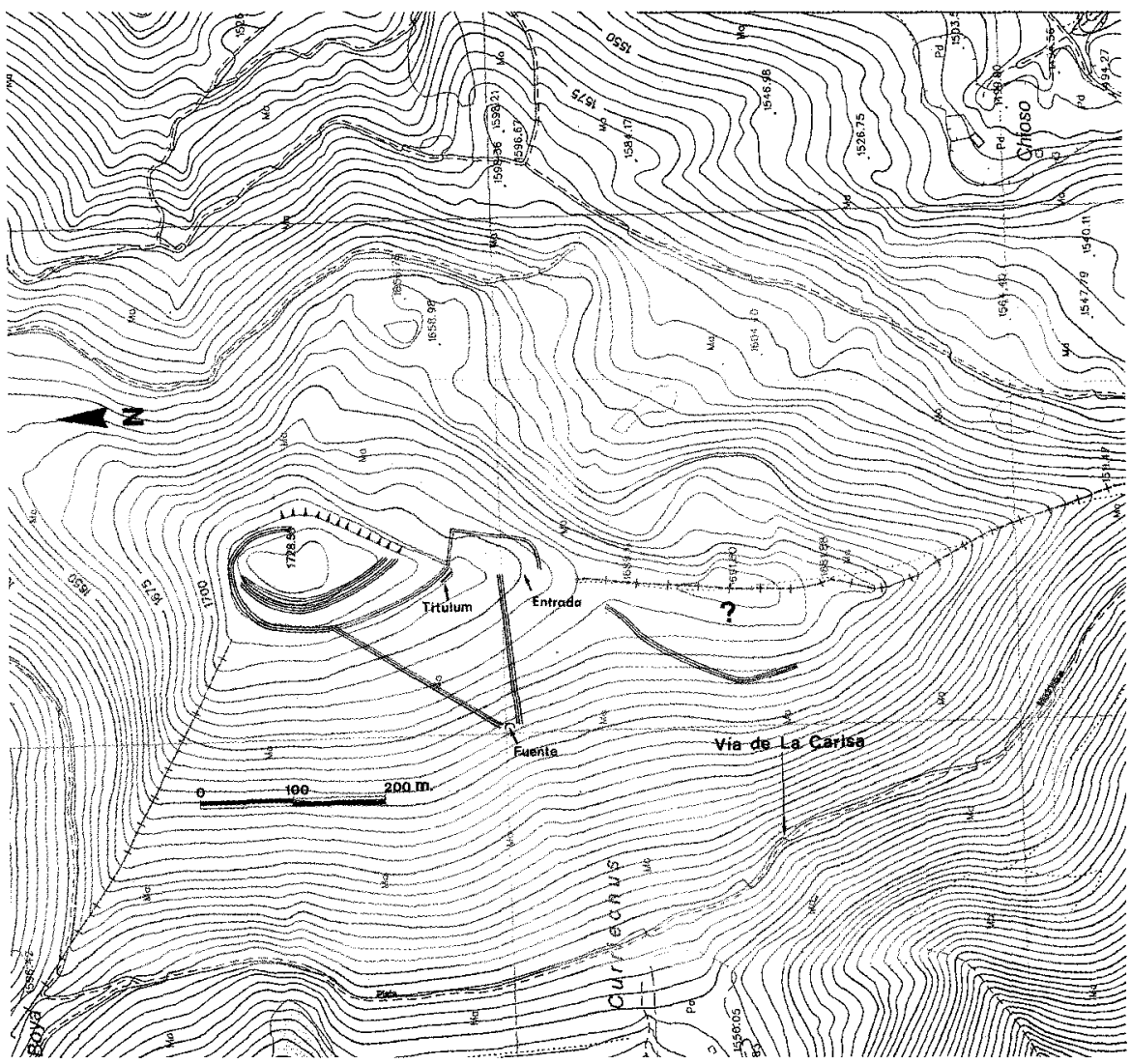

Fig. 1. Croquis de planta de las obras de fortificación reconocidas en el campamento antes de la limpieza y excavación.

en el norte de León (Menéndez Pidal, 1897). Así y todo, el topónimo aparece materializado por excelencia en las inmediaciones de Pajares, donde se fundó en el siglo XI la colegiata de Arbás y en cuya vecindad se encuentra la sierra de los Pasos de Arbás. Todavía más en concreto, dejando a un lado el problema de la localización de los montes en cuestión y su relación con la Vía Carisa, el historiador Carvallo supone que los romanos rompieron el frente precisamente en los valles de Lena y Quirós, por los que se condujeron hasta el centro de la región.

Otras opiniones del siglo XIX señalaban que en La Romía y en las majadas de Fierros, lugares del valle de Pajares, habían acampado las tropas romanas, recibiendo sepultura sus numerosas bajas de guerra en 


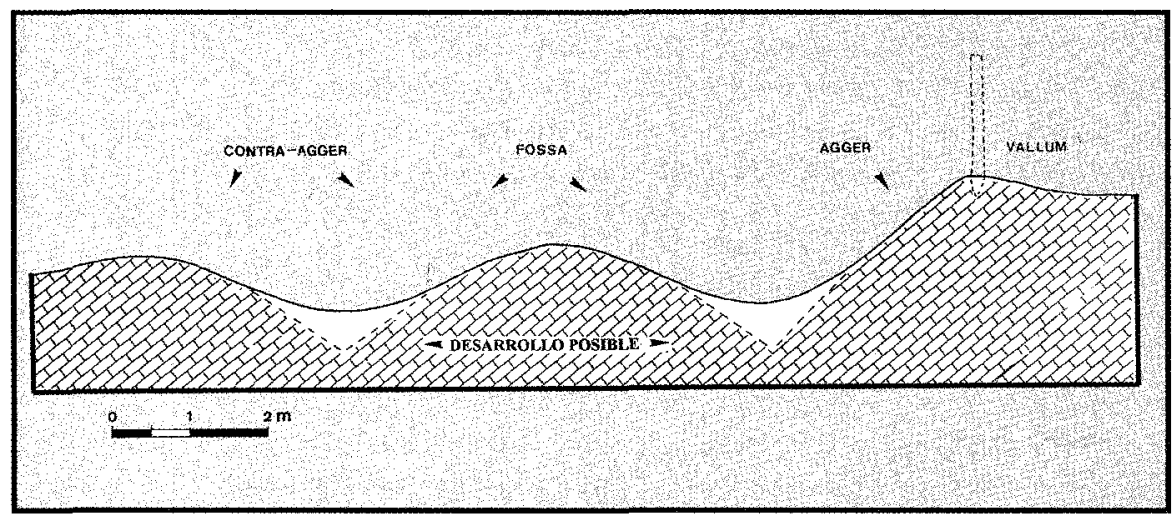

Fig. 2. Sección topográfica de un vallum del dispositivo convergente exterior.

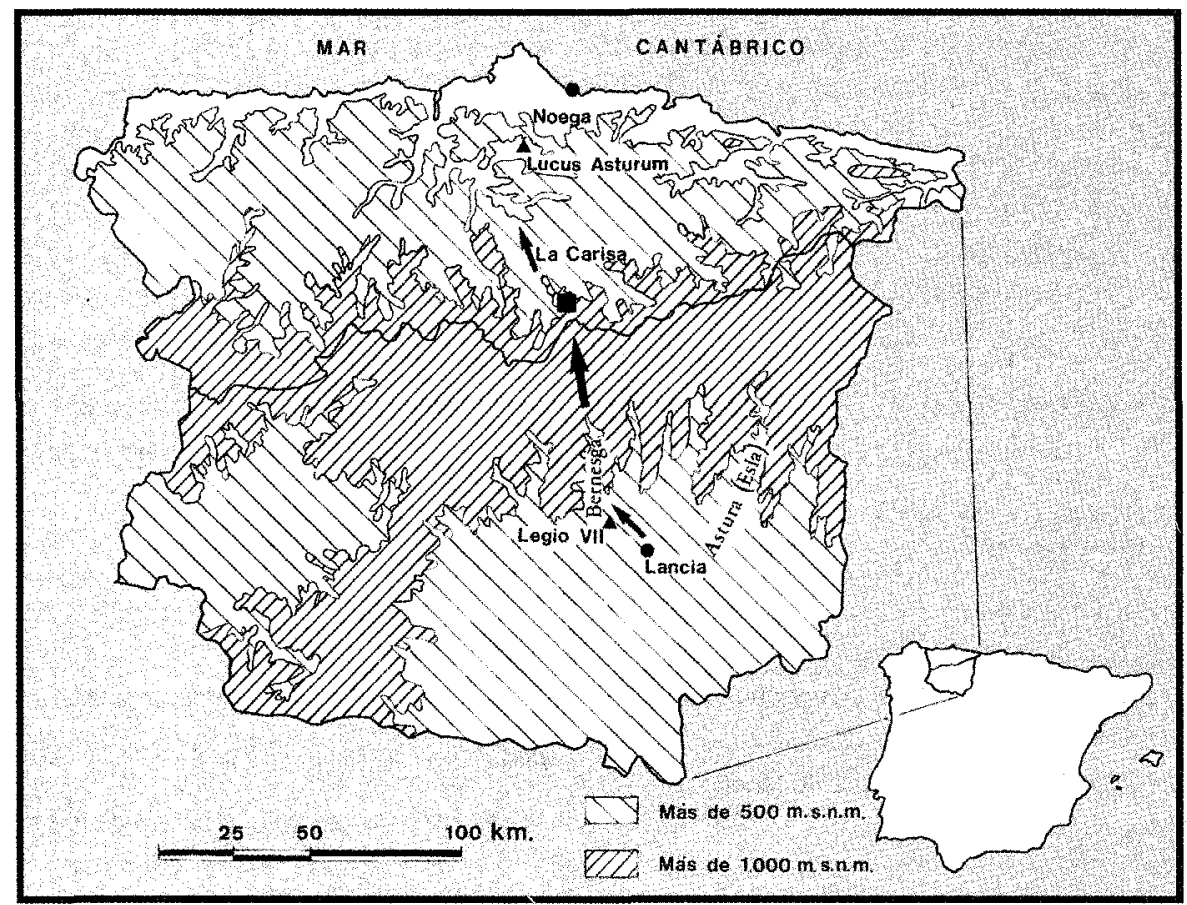

Fig. 3. Mapa del escenario conocido del Bellum Asturicum y algunos lugares de interés. 
Campomanes, donde se dice aparecieron muchas monedas lápidas y sepulturas romanas en el siglo XVII (Caunedo, 1858), mientras en Buschumoso habría tenido lugar el refugio final de ástures y cántabros (Menéndez Pidal, 1897).

Pero más interesante fue la interpretación que a mediados del siglo XIX hizo de los montes de La Carisa el escenario del episodio del Mons Medullius, fundamentada en diversos hallazgos arqueológicos, como los cascos militares, las fortificaciones de La Carisa y el foso que rodeaba un monte contiguo (Tuñón y Quirós, 1860a).

Es plausible que esas teorías se correspondieran con leyendas populares - ¿fuente de inspiración, mero reflejo o influencias mutuas?- Es así que, quizá como reminiscencia de posos eruditos, era tradición entre los viejos de hace medio siglo que en el puerto de La Carisa había tenido lugar una batalla en la que intervino el general Carís (Cabal, 1953). También era creencia popular que en Las Yanas de Curriellos habían estado atrincherados los moros mucho tiempo, sufriendo una matanza tremenda en Buschimoso, donde está La Fuente de El Sepu, tan grande que durante dos años hubo sangre rodando por ella arriba. Los moros que escaparon de esta huyeron hacia Pindiella donde los cogieron y los colgaron - «pendiórenlos»- de una viga, de donde quedó el nombre de Pindiella (leyenda recogida por Gausón Fernández de boca de Marcelino Fernández Miranda, de Santibáñez de Murias, quien la había escuchado a su abuelo).

\section{BIBLIOGRAFÍA}

CaAvallo, L.A. DE (1695): Antigüedades y cosas memorables del Principado de Asturias, Madrid, (Reed. Salinas, 1984).

CABAL, C. (1953): La Asturias que venció Roma, Instituto de Estudios Asturianos, Oviedo.

CAUNEDO, N. C. de, 1858, Album de un viaje por Asturias, Imprenta de D.G. Solís, Oviedo.

Carretero Vaquero, S., y Romero Carnicero, M. ${ }^{2}$.V. (1996): Los Campamentos Romanos de Petavonium (Rosinos de Vidriales, Zamora), Fundación Rei Afonso Henriques.

ConcePción, J. (1995): Por los pueblos de Lena, Ed. Trea.

Diego SANTOS, F. (1979): «Luggones/Luggoni», Estudios ofrecidos a Emilio Alarcos Llorach, IV, págs. 319-323.

FERNÁNDEZ OCHOA, C. (1977): 1982, Asturias en la época romana, Monografías Arqueológicas, 1, Universidad Autónoma de Madrid.

ForNI, G. (1970): «L'occupazione militare romana della Spagna nord-occidentale: analogie e paralleli», Legio VII Gemina, Diputación Provincial de León, págs. 205-225.

GARCía ARIAS, X.L. (2000): Pueblos asturianos: el porqué de sus nombres, $2 .^{\mathrm{a}}$ ed. corregida y aumentada, Alborá Llibros, Gijón.

GonzÁlez FERNÁNDEZ, M. ${ }^{\mathrm{a}}$ L. (1999): «De campamento a civitas. La primera fortificación urbana de Asturica Augusta (Astorga, León)», Numantia, 7, Arqueología en Castilla y León 1995/1996, pags. 95-115.

GonzÁlez Y FERNÁNDEZ-VALLES, J.M. (1966): «Catalogación de los castros asturianos», Archivum, XVI, págs. 255-291. 
- (1978): Asturias Protohistórica, Historia de Asturias, 2, Ed. Ayalga.

MAYA GonzÁLEZ, J.L. (1983): «La cultura castreña asturiana: De los orígenes a la romanización", Indignenismo y romanización en el Conventus Asturum, págs. 11-44.

- (1988): La cultura material de los castros asturianos, Estudios de la Antigüedad, 4/5, Universitat Autónoma de Barcelona.

MenÉndez PIDAl, J. (1897): "Lena", Asturias (Ed. de O. Bellmunt y F. Canella), Tom. II, págs. 283-331.

Peralta Labrador, E. (1999): «Los castros cántabros y los campamentos romanos de Toranzo y de Iguña. Prospecciones y sondeos (1996-97)», Las Guerras Cántabras, Fundación Marcelino Botín, págs. 201-276.

- (2001): «Die augusteische Belagerung von la Espina del Gallego (Kantabrien, Sapien)», Germania, 79, págs. 21-42.

RedDÉ, M. (1999): "César ante Alesia», Las Guerras Cántabras, Fundación Marcelino Botín, págs. 119-144.

SÁNCHEZ-PALENCIA, F.J., «El campamento romano de Valdemeda, Manzaneda (León): ocupación militar y explotación aurífera en el NW. Peninsular», Numantia, II, págs. 227-234.

SYME, R. (1970): «The conquest of north-west Spain», Legio VII Gemina, Diputación Provincia! de León, págs. 78-107.

TuÑón Y QuiRós, E.G. (1860a): «Guerra de los romanos en Asturias», en González Solís y Cabal, P., Memorias asturianas, 1890, págs. 188-194.

- (1860b) «Objeto arqueológico», en González Solís y Cabal, P., Memorias asturianas, 1890, págs. 228-229.

- (1865) "Antigüedades de Asturias», en González Solís y Cabal, P., Memorias asturianas, 1890, págs. 228 .

VILLA VALDÉS, A. (2000): "Aportaciones al estudio de la evolución del espacio urbano castreño en el occidente de Asturias (siglos IV A.C. - I D.C.)", Actas do $3 .^{\circ}$ Congresso de Arqueologia Peninsular, Vol. V, Proto-história da Península Jbérica, Porto, págs. 507-514.

WeBster, G. (1988): Fortress into City. The consolidation of Roman Britain firs century AD, B.T. Batsford Ltd., London. 